\title{
PRESYNAPTIC ACTION OF NEUROTENSIN ON CULTURED VENTRAL TEGMENTAL AREA DOPAMINERGIC NEURONES
}

\author{
M. LEGAULT, ${ }^{1}$ P. CONGAR, ${ }^{1}$ F. J. MICHEL and L.-E. TRUDEAU* \\ Départements de Pharmacologie et de Psychiatrie, Centre de Recherche en Sciences Neurologiques, \\ Centre de Recherche Fernand Seguin, Université de Montréal, Montréal, QC, Canada
}

\begin{abstract}
Dopamine-containing neurones of the ventral tegmental area express neurotensin receptors which are involved in regulating cell firing and dopamine release. Although indirect evidence suggests that some neurotensin receptors may be localised on the nerve terminals of dopaminergic neurones in the striatum and thus locally regulate dopamine release, a clear demonstration of such a mechanism is lacking and a number of indirect sites of action are possible. We have taken advantage of a simplified preparation in which cultured rat ventral tegmental area dopaminergic neurones establish nerve terminals that co-release glutamate to determine whether neurotensin can act at presynaptic sites. We recorded glutamatemediated synaptic currents that were generated by dopaminergic nerve terminals as an index of presynaptic function. The neurotensin receptor agonist NT(8-13) caused an inward current and an enhancement of the firing rate of dopaminergic neurones together with an increase in the frequency of spontaneous glutamate receptor-mediated excitatory postsynaptic currents (EPSCs). Incompatible with a direct excitatory action on nerve terminals, NT(8-13) failed to change the amplitude of individual action potential-evoked EPSCs or the frequency of miniature EPSCs recorded in the presence of tetrodotoxin. However, NT(8-13) reduced the ability of terminal D2 dopamine receptors to inhibit action potentialevoked EPSCs in isolated dopaminergic neurones. Taken together, our results suggest that in addition to its well-known somatodendritic excitatory effect leading to an increase in firing rate, neurotensin also acts on nerve terminals. The main effect of neurotensin on nerve terminals is not to produce a direct excitation, but rather to decrease the effectiveness of D2 receptor-mediated presynaptic inhibition. (C) 2002 IBRO. Published by Elsevier Science Ltd. All rights reserved.
\end{abstract}

Key words: glutamate, dopamine, nerve terminal, patch-clamp, primary culture, rat.

Neurotensin (NT) is a 13 amino acid peptide that is closely associated with major dopaminergic nuclei (Carraway and Leeman, 1973; Kitabgi et al., 1989; Quirion, 1983; Rostene et al., 1997) and can be synthesised by dopaminergic neurones themselves (Seroogy et al., 1988). When applied to the ventral tegmental area (VTA), NT increases the firing rate of dopaminergic neurones (Pinnock, 1985; Seutin et al., 1989; Werkman et al., 2000), evokes dopamine release at the terminals of these cells in the ventral striatum and prefrontal cortex (Kalivas and Duffy, 1990; Laitinen et al., 1990; Sotty et al., 2000, 1998) and facilitates dopamine-dependent behaviours (Bissette et al., 1976; Holmes and Wise,

1 Both authors contributed equally to this work.

*Corresponding author. Tel.: +1-514-343-5692; fax: +1-514-3432291.

E-mail address: louis-eric.trudeau@umontreal.ca (L.-E. Trudeau). Abbreviations: AMPA, ( \pm )- $\alpha$-amino-3-hydroxy-5-methylisoxazole4-proprionic acid; ANOVA, analysis of variance; CNQX, 6-cyano-7-nitroquinoxaline-2,3-dione; EGTA, ethylene glycolbis(2-amino ethyl-ether)- $N, N, N^{\prime}, N^{\prime}$-tetraacetic acid; EPSC, excitatory postsynaptic current; GFAP, glial fibrillary acidic protein; HEPES, $\quad N$-(2-hydroxyethyl)piperazine- $N^{\prime}$-(2-ethane-sulfonic acid); mEPSC, miniature excitatory postsynaptic current; NT, neurotensin; NT(8-13), 8-13 fragment of neurotensin; NTR1/2, type $1 / 2$ neurotensin receptors; TTX, tetrodotoxin; VTA, ventral tegmental area.
1985; Jolicoeur et al., 1984; Rompre and Perron, 2000; Rompre et al., 1992; Rompre and Gratton, 1992, 1993; Sotty et al., 1998; Steinberg et al., 1995).

The effects of NT on dopamine release are thought to be mediated primarily by somatodendritic NT receptors that regulate the firing rate of dopaminergic neurones. NT is known to depolarise various neurones (Alonso et al., 1994; Audinat et al., 1989; Jolas and Aghajanian, 1996), including midbrain dopaminergic neurones (Jiang et al., 1994; Nalivaiko et al., 1998). The depolarising action of NT on dopaminergic neurones occurs through the activation of cationic conductances together with the closure of potassium conductances (Farkas et al., 1996; Jiang et al., 1994; Wu et al., 1995). Such depolarising actions of NT at the level of the cell bodies of dopaminergic neurones provide a simple explanation for NT's ability to increase dopaminergic neurotransmission (Gully et al., 1997).

It is possible that NT also acts directly on the nerve terminals of dopaminergic neurones. This hypothesis is supported by two observations. First, the destruction of midbrain dopaminergic neurones by 6-hydroxydopamine lesions decreases the number of NT binding sites in the nucleus accumbens, compatible with a presynaptic localisation of NT receptors (Quirion et al., 1985; Schotte and Leysen, 1989). Second, NT can facilitate the evoked release of dopamine from brain slices prepared from the striatum (Faggin et al., 1990; Heaulme et al., 1997; 
Hetier et al., 1988) and in vivo (Ferraro et al., 1997). Although these results are compatible with a direct presynaptic effect of NT, they cannot exclude the possibility that in dopaminergic terminal regions NT acts indirectly. For instance, local application of NT to the striatum increases extracellular glutamate (Ferraro et al., 1998). This glutamate could be released from cortico-striatal fibres and may then facilitate or evoke dopamine release presynaptically (Cheramy et al., 1994; Desce et al., 1991; Glowinski et al., 1988; Romo et al., 1986). The mechanism of action of NT on dopaminergic nerve terminals is thus presently unclear.

In order to better characterise the mechanism of action of NT on dopaminergic neurones and to test for a presynaptic site of action of this peptide on these cells, we have conducted experiments on cultured VTA dopaminergic neurones. These neurones, at least in culture, form synaptic terminals that release glutamate at synapses in addition to dopamine. By monitoring glutamate-mediated synaptic currents generated by dopaminergic neurones we can monitor the quantal release properties of synapses formed by these neurones (Bourque and Trudeau, 2000; Congar and Trudeau, 1999; Sulzer et al., 1998). Using this advantageous system, we have characterised the mechanism whereby the NT receptor agonist NT(8-13) enhances neurotransmitter release from dopaminergic neurones.

\section{EXPERIMENTAL PROCEDURES}

\section{Cell culture}

VTA primary cultures were prepared from the brains of neonatal rats (postnatal days 1-3), according to a recently described procedure (Bourque and Trudeau, 2000; Michel and Trudeau, 2000; Trudeau, 2000). Rat pups were cryoanaesthetised and all animal handling conformed to Université de Montréal animal ethics committee guidelines. All efforts were made to minimise the number of animals used and their suffering. In brief, a coronal slice with an approximate thickness of $1.5 \mathrm{~mm}$ was cut by hand at the level of the midbrain flexure. The left and right VTA were dissected out using a custom tissue micro-punch. The tissue was incubated in papaïn for $30 \mathrm{~min}$ and dissociated by trituration. Dissociated cells were plated on $15 \mathrm{~mm}$ diameter round coverslips (Ted Pella, Reading, PA, USA) which were coated with collagen/poly-L-lysine. For single neurone 'micro-dot' cultures, neurones were plated onto agarose-covered coverslips sprayed with collagen and poly-D-lysine droplets to produce small areas conducive to cell growth. As previously described (Bourque and Trudeau, 2000), this permitted the establishment of small patches of cells containing one or more astrocytes together with individual dopaminergic neurones. Under such conditions, isolated dopaminergic neurones establish dopaminergic and glutamatergic synaptic connections onto their own dendritic arbour (Bourque and Trudeau, 2000; Sulzer et al., 1998). Cells were maintained in basal Eagle medium (GibcoBRL, Montréal, QC, Canada) to which was added 5\% foetal calf serum (Sigma, St. Louis, MO, USA) and Mito+ serum additive (VWR Canlab, Montréal, QC, Canada). The culture medium was replaced in part with fresh medium biweekly. For most experiments, cultures were used between 12 and 28 days after plating.

\section{Electrophysiology}

Synaptic currents were measured from whole-cell patch-clamp recordings obtained at room temperature $\left(\sim 22^{\circ} \mathrm{C}\right)$ from neurones using a Warner PC-501 patch-clamp amplifier (Warner Instruments, Hamden, CT, USA). Patch pipettes were pulled from borosilicate glass and had a resistance of approximately $5 \mathrm{M} \Omega$. All excitatory synaptic events were mediated by $\alpha$-amino-3-hydroxy-5-methylisoxazole-4-proprionic acid (AMPA)/ kainate receptors because they were completely blocked by 6-cyano-7-nitroquinoxaline-2,3-dione (CNQX) and insensitive to DL-2-amino-5-phosphoraleric acid (AP5) at the usual holding potential of $-50 \mathrm{mV}$ (not shown). Most experiments were performed in the presence of the $\mathrm{GABA}_{\mathrm{A}}$ receptor antagonist SR95531 (Mienville and Vicini, 1987) to block GABA receptormediated inhibitory synaptic currents. Signals were low-pass filtered at $1 \mathrm{kHz}$ and digitised at $5 \mathrm{kHz}$ using a Digidata $1200 \mathrm{~A} / \mathrm{D}$ converter and pCLAMP 7 software (Axon Instruments, Foster City, CA, USA). Action potential recording experiments were performed using an Axopatch 200B patch-clamp amplifier (Axon Instruments), a BNC-2090 A/D converter (National Instruments, Austin, TX, USA) and VClamp software from Prairie Technologies LLC (Middleton, WI, USA). In electrophysiological experiments, series resistance was usually between 7 and $12 \mathrm{M} \Omega$ and was compensated to approximately $70-80 \%$. Cells which showed notable changes in series resistance or resting potential during an experiment were rejected. Normal extracellular saline consisted of (in $\mathrm{mM}$ ): $\mathrm{NaCl} 140, \mathrm{MgCl}_{2} 2, \mathrm{CaCl}_{2}$ 2, $\mathrm{KCl} 5$, HEPES 10, sucrose 6, glucose $10(\mathrm{pH} 7.35)$. For synaptic current recordings, patch pipettes contained (in $\mathrm{mM}$ ): Cs-gluconate 117.5, $\mathrm{NaCl} 10, \mathrm{MgCl}_{2}$ 4, EGTA 5, Mg-ATP 2 , Tris-GTP 0.2, HEPES 15 ( $\mathrm{pH}$ 7.35). For action potential recordings and single-cell autaptic current recordings, patch pipettes contained (in $\mathrm{mM}$ ): $\mathrm{KMeSO}_{4}$ 140, $\mathrm{NaCl} 10$, EGTA 0.1, Mg-ATP 4, Tris-GTP 0.5, HEPES 10 (pH 7.35). In autaptic current recording experiments performed on isolated dopaminergic neurones, the identity of the cell as dopaminergic was determined by immunolabelling for tyrosine hydroxylase or by the sensitivity of its synaptic current to the D2 receptor agonist quinpirole. As we have previously shown (Congar and Trudeau, 1999), in mesencephalic cultures, only dopaminergic neurones show quinpirole-mediated presynaptic inhibition. Sensitivity to D2 receptor agonists has also been shown both in culture and in slice as a valid phenotypic marker of dopaminergic neurones (Lacey et al., 1989; Rayport et al., 1992). Electrophysiological signals were analysed using Clampfit (Axon Instruments) and 'Mini Analysis' 4.0 (Synaptosoft, Leonia, NJ, USA). In electrophysiological experiments, NT(8-13) and other drugs were applied by bath perfusion using a flow rate of $1-2 \mathrm{ml} / \mathrm{min}$. The capacity of the experimental chamber was approximately $200 \mu \mathrm{l}$.

\section{Statistical analysis}

Data in the text and figures are represented as mean \pm S.E.M Group data were analysed using analyses of variance (ANOVAs) and post-hoc tests, as indicated. In other experiments, individual means were compared using Student's paired $t$-test, where appropriate. A probability level at or below 0.05 was considered statistically significant.

\section{Immunolabelling}

Immunolocalisation of tyrosine hydroxylase was used to identify dopaminergic neurones. The proportion of tyrosine hydroxylase-positive neurones in the cultures was variable but was usually between 30 and $40 \%$. This percentage was estimated by counting the number of dopaminergic neurones as well as the total number of neurones in six fields across individual coverslips. In experiments which involved the recording of NT-evoked action potentials, of miniature excitatory postsynaptic currents (mEPSCs) or of autaptic currents, the recording location was marked using a pipette filled with $0.2 \mu \mathrm{m}$ diameter green fluorescent microspheres (Molecular Probes, Eugene, OR USA) which adhered to the cellular surface of closely located astrocytes (see Fig. 4A). This facilitated the subsequent identification of dopaminergic neurones by immunofluorescence using 
a mouse monoclonal primary antibody (Sigma Chemical Co. St. Louis, MO, USA) and a secondary antibody coupled to Alexa-546 (Molecular Probes). In other experiments, dopaminergic neurones were localised using a biotin-conjugated secondary antibody and peroxidase-conjugated streptavidin (Jackson Immunoresearch Laboratories, West Grove, PA, USA). Diaminobenzidine was used as the chromogen. Glial fibrillary acidic protein (GFAP) was localised using a polyclonal antibody (Sigma) and permitted identification of astrocytes. An antiGABA antibody (Sigma) was used to identify GABAergic neurones. Fluorescent secondary antibodies were coupled to Alexa-488 or Alexa-546. In some experiments, immunofluorescence data were acquired as stacks of images at multiple focal planes $(0.5 \mu \mathrm{m}$ steps $)$ and out of focus signal was rejected by digital deconvolution using ISee software by Inovision Corporation (Raleigh, NC, USA)

\section{Drugs}

Except for tetrodotoxin (TTX) (Alomone laboratories, Jerusalem, Israel), all chemicals were obtained from Sigma. The 813 fragment of NT [NT(8-13)] was used as an NT receptor agonist in the present set of experiments. This peptide is the shortest fully active fragment of NT.

\section{RESULTS}

Experiments were performed on primary cultures of rat VTA. These preparations contained both neurones and astrocytes. Dopaminergic neurones could be identified by immunoreactivity against tyrosine hydroxylase (Fig. 1A) and comprised between 30 and $40 \%$ of the neuronal population. Other neurones were mostly GABAergic (Michel and Trudeau, 2000), as shown by their immunoreactivity to GABA (not shown) [see also (Sulzer et al., 1998)]. A glial cell monolayer covered most of the coverslip surface. These cells were exclusively astrocytes as suggested by their immunoreactivity to GFAP (not shown).

Action of NT(8-13) on membrane current and cellular excitability

We first determined whether like in vivo, NT could cause inward currents and enhance the firing of VTA neurones. Recordings were initially performed at a holding potential of $-50 \mathrm{mV}$ from randomly selected neurones. Compatible with a direct depolarising action of $\mathrm{NT}(8-13)$, we found that NT(8-13) $(100 \mathrm{nM})$ caused a detectable slow inward current, often beginning abruptly after a delay of 10-20 s (Fig. 1B). In initial experiments we noticed that this occurred together with a rise in the frequency of spontaneous CNQX-sensitive AMPA receptor-mediated excitatory postsynaptic currents (EPSCs) (Fig. 1B). In VTA cultures, these synaptic events arise from the terminals established by dopaminergic neurones which are known to release glutamate in addition to dopamine (Bourque and Trudeau, 2000; Congar and Trudeau, 1999; Sulzer et al., 1998). Slow inward currents evoked by NT(8-13) had small amplitude and displayed variable time-courses. The time-course was sometimes biphasic, with a smaller early phase, followed by a larger more delayed phase (Fig. 1C). The amplitude of such events was more readily measured in the presence of TTX where synaptic activity was less abundant (Fig. 1C). Such inward currents were detected in 10 out of 20 cells recorded at a holding potential of -50 $\mathrm{mV}$ in the presence of TTX. The observation that only half of the neurones showed such an inward current is to be expected considering the percentage of dopaminergic neurones in the cultures (see Experimental procedures). On average, NT(8-13)-evoked slow inward currents had a maximal amplitude of $22 \pm 5 \mathrm{pA}$ and an average duration of $69 \pm 10 \mathrm{~s}(n=10)$. These responses displayed complete desensitisation: in six cells where NT(8-13) was applied a second time $5 \mathrm{~min}$ after the first application, no NT-evoked inward currents were detected. Because the ionic mechanism of such currents evoked by NT in dopaminergic neurones has been previously characterised (Jiang et al., 1994), this was not further investigated in the present report.

We also recorded membrane potential and action potential firing in VTA neurones. These recordings were performed from confirmed, tyrosine hydroxylasepositive dopaminergic neurones (see Experimental procedures). We found that $100 \mathrm{nM} \mathrm{NT(8-13)} \mathrm{caused} \mathrm{a}$ marked increase in the frequency of spontaneously occurring action potentials (Fig. 1D) in identified dopaminergic neurones. In some cells, this was accompanied by occasional burst-like discharge and a reduction of action potential amplitude (Fig. 1D). The basal firing rate was highly variable $(0.3 \pm 0.15 \mathrm{~Hz})(n=7)$ and some neurones were initially quiescent. Firing rate was thus quantified as a change in firing rate (delta) over time using $15 \mathrm{~s}$ bins. A baseline firing rate was calculated from the mean of the first four bins (60 s) and this value was then subtracted from the value of each bin. In normal saline $100 \mathrm{nM} \mathrm{NT(8-13)} \mathrm{caused} \mathrm{a} \mathrm{robust} \mathrm{change} \mathrm{in} \mathrm{delta}$ firing rate. Delta firing rate peaked $30 \mathrm{~s}$ after the end of the application of NT(8-13) (Fig. 1D, E) and reached $18.6 \pm 6.1$ action potentials per $15 \mathrm{~s}$ bin $(n=7)$. A oneway ANOVA confirmed an overall difference between time points $(F=2.6(15), P<0.02)$, while a Fisher LSD post-hoc test confirmed that a significant increase in firing rate occurred at time points beginning just before the end of the NT(8-13) application (Fig. 1E).

\section{Enhancement of spontaneous EPSC frequency}

We next quantified the NT-evoked enhancement in spontaneous EPSC frequency. Event number was quantified in $1 \mathrm{~min}$ bins and the number of events in the baseline period compared to the $1 \mathrm{~min}$ bin in the presence of NT(8-13). Although the extent of the effect was variable, we found that in all cells NT(8-13) $(100 \mathrm{nM})$ induced a clear, prolonged and reversible increase in the frequency of spontaneous EPSCs (Fig. 2A, B). The latency of this effect was variable. On average, NT(813) caused a $1048 \pm 565 \%$ increase in spontaneous EPSC frequency (Student's paired $t$-test, $P<0.02$ ) $(n=5)$. This enhancement was short-lasting and event frequency returned to baseline level by $2 \mathrm{~min}$ after washout of NT(8-13) $(148.5 \pm 49.5 \%$ of baseline). 
A

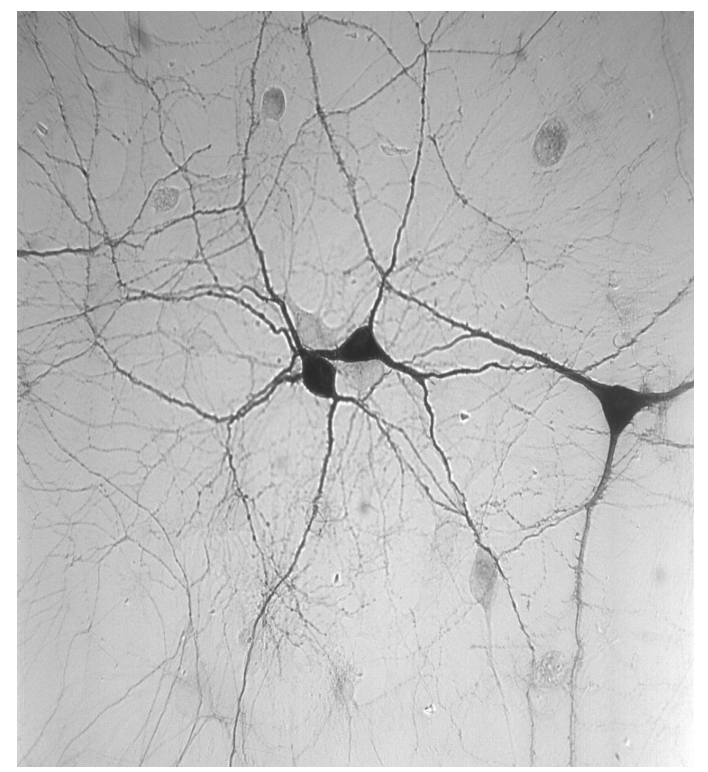

B

\section{NT(8-13)}

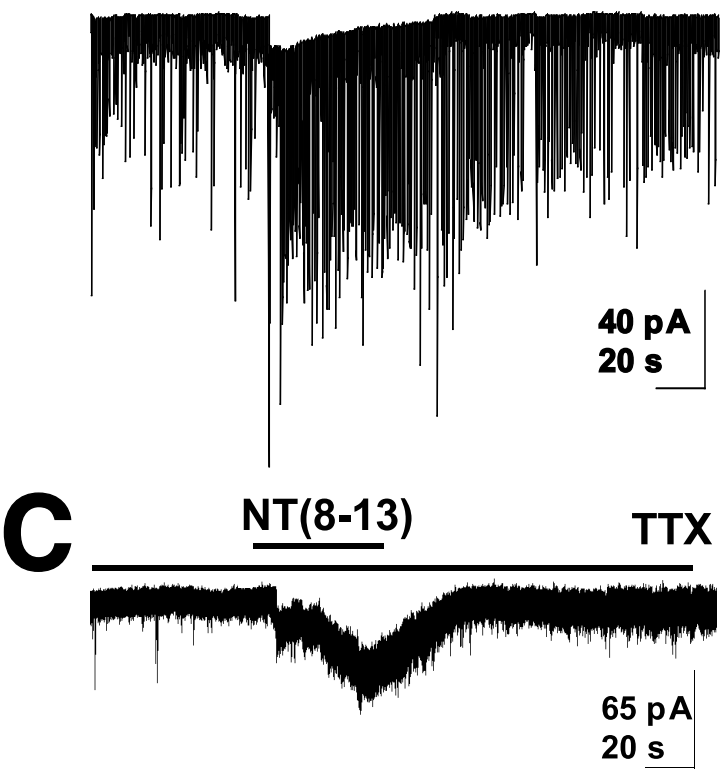

\section{NT(8-13)}
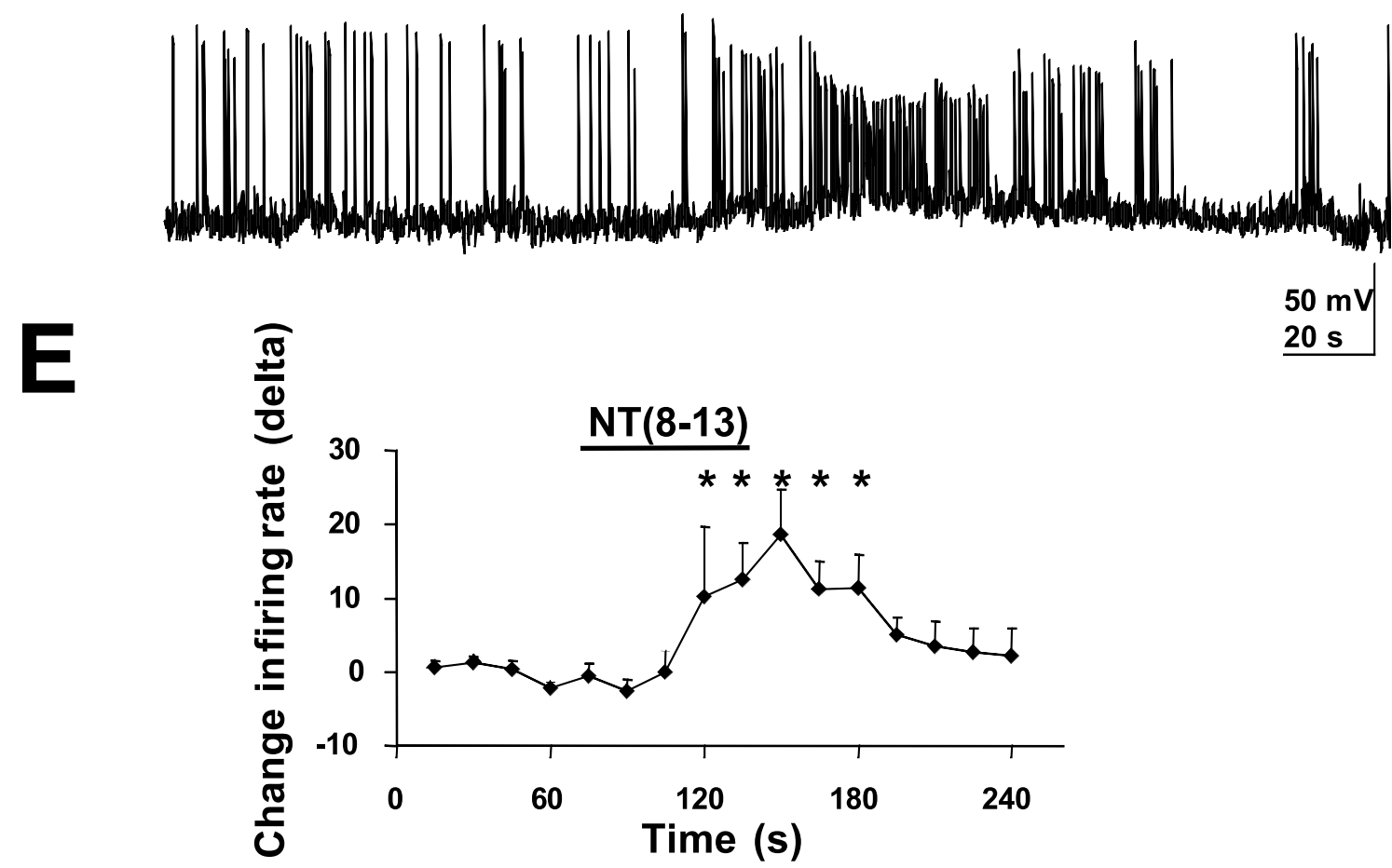

Fig. 1. NT(8-13) evokes slow inward currents and action potential firing in VTA neurones. (A) Dopaminergic neurones were identified in VTA cultures by their immunoreactivity to tyrosine hydroxylase. The primary antibody was visualised using a peroxidase-conjugated secondary antibody. Scale bar $=15 \mu \mathrm{m}$. (B) Whole-cell voltage-clamp recording from a VTA neurone in normal saline at a holding potential of $-50 \mathrm{mV}$. Perfusion of $100 \mathrm{nM} \mathrm{NT}(8-13)$ for 60 s caused a slow inward current accompanied by an increase in the frequency of spontaneous EPSCs. (C) In another neurone recorded at a holding potential of $-50 \mathrm{mV}$ in the presence of TTX, perfusion of $100 \mathrm{nM} \mathrm{NT}(8-13)$ for $60 \mathrm{~s}$ also caused a slow inward current. Note that the apparently broad peak-to-peak noise is due to the compressed time scale of the trace. (D) Whole-cell current-clamp recording from a VTA neurone in normal saline. Perfusion of $100 \mathrm{nM} \mathrm{NT(8-13)}$ for $60 \mathrm{~s}$ caused an enhancement of spontaneously occurring action potentials. Resting potential was $-55 \mathrm{mV}$. (E) Summary graph representing the average enhancement of action potential firing by NT(8-13) $(100 \mathrm{nM})$ in identified dopaminergic neurones in normal saline. The change in firing rate over time is expressed as a difference score (delta) between the average firing rate within $15 \mathrm{~s}$ bins and the average firing rate within the four initial bins acquired before agonist application $(* P<0.05)$. 


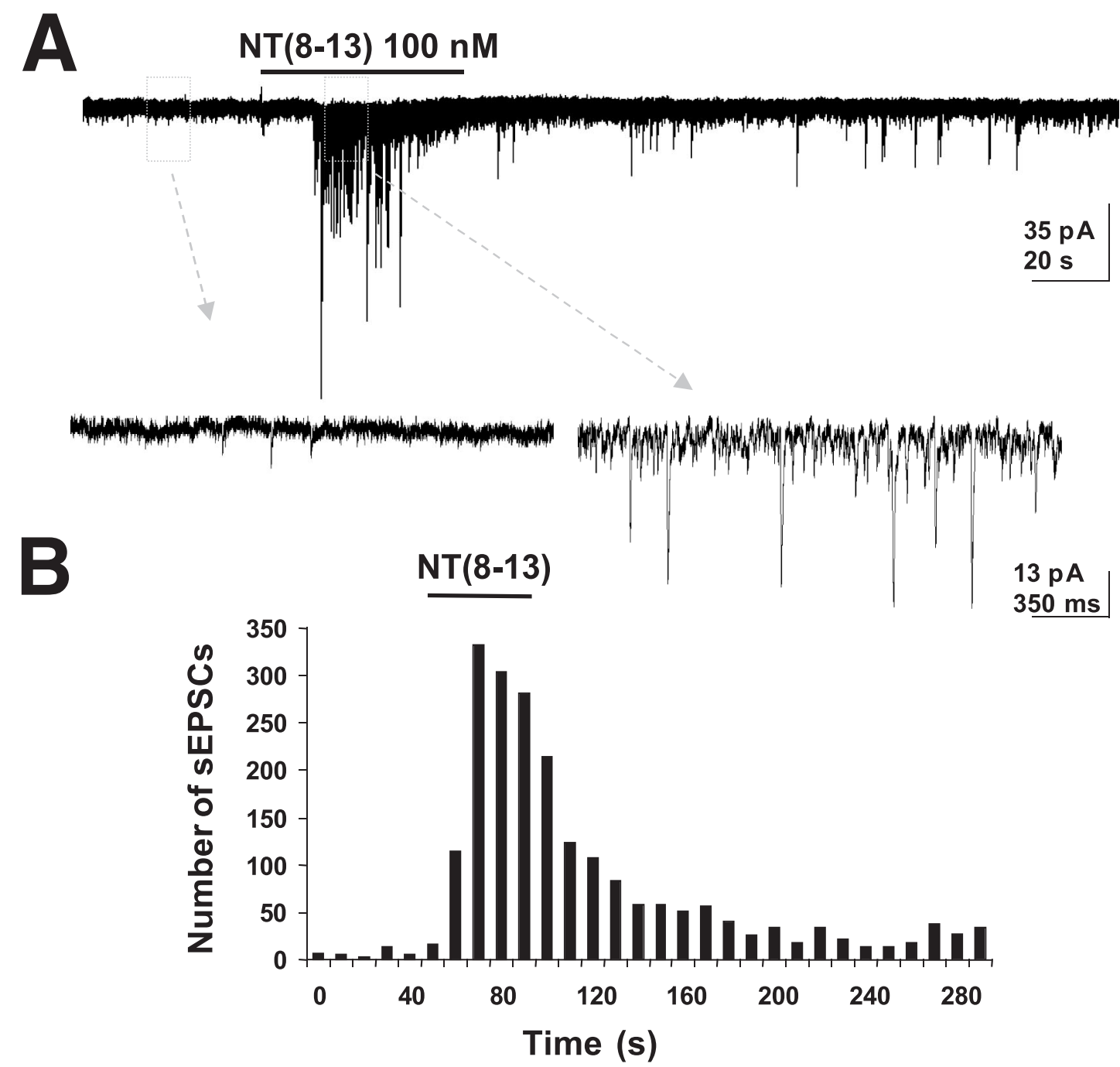

Fig. 2. Enhancement of spontaneous EPSC frequency by NT(8-13). (A) Whole-cell voltage-clamp recording of a VTA neurone in normal saline containing $10 \mu \mathrm{M}$ SR-95531 to block GABA $\mathrm{A}$ receptors. The holding potential was $-50 \mathrm{mV}$. NT(8-13) $(100 \mathrm{nM})$ caused a large increase in the frequency of spontaneous EPSCs. The lower traces represent segments of the same recording at a finer temporal resolution to show individual synaptic events. (B) Histogram representing the spontaneous EPSC frequency of the data shown in (A). The bin size was $10 \mathrm{~s}$. NT(8-13) was applied for $60 \mathrm{~s}$ after the first minute of recording.

\section{Evidence for a presynaptic neuromodulatory action}

The enhancement of spontaneous EPSC frequency caused by NT(8-13) could have resulted solely from the increase in the firing rate of dopaminergic neurones. Alternately, it could have been caused at least in part by an enhancement of the efficacy of neurotransmitter release. The latter mechanism would be expected if NT(8-13) acted on nerve terminals and would be predicted to be accompanied by an increase in the frequency of mEPSCs. To record mEPSCs, action potential-evoked EPSCs were blocked using TTX $(0.5 \mu \mathrm{M})$ and recordings were obtained from non-dopaminergic neurones that were confirmed to be surrounded by fine processes and varicosities emanating from dopaminergic neurones (Fig. 3A). Under these conditions, NT(8-13) $(100 \mathrm{nM})$ produced no change in $\mathrm{mEPSC}$ frequency $(117.2 \pm 16.0 \%$ of control; Student's paired $t$-test, $P>0.05 ; n=10$ ) (Fig. 3B). The amplitude of mEPSCs was also unchanged $(99.8 \pm 2.5 \%$ of control, Student's paired $t$-test, $P>0.05$; $n=10$ ), a finding confirmed by an analysis of cumulative probability distributions of mEPSC amplitudes (Kolmogorov-Smirnov test, $P>0.05$ ) (Fig. 3C). These results suggest that action potentials are necessary for the enhancement of spontaneous EPSC frequency by NT(8-13) and that NT(8-13) does not act to directly facilitate neurotransmitter release by depolarising glutamate-releasing nerve terminals established by dopaminergic neurones.

To examine further the action of $\mathrm{NT}(8-13)$ on the nerve terminals of dopaminergic neurones, we performed additional experiments to determine the effect of NT(813) on glutamate-mediated EPSCs evoked by single action potentials in dopaminergic neurones. For these 


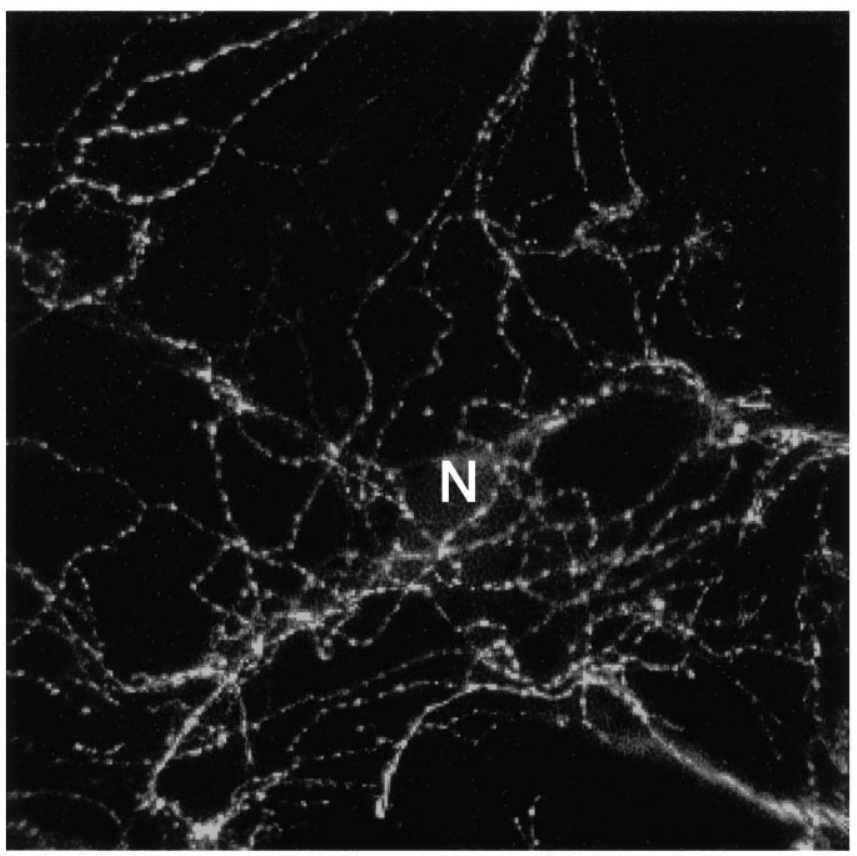

B

A

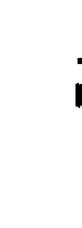

NT(8-13) 100 nM TTX

(in

C

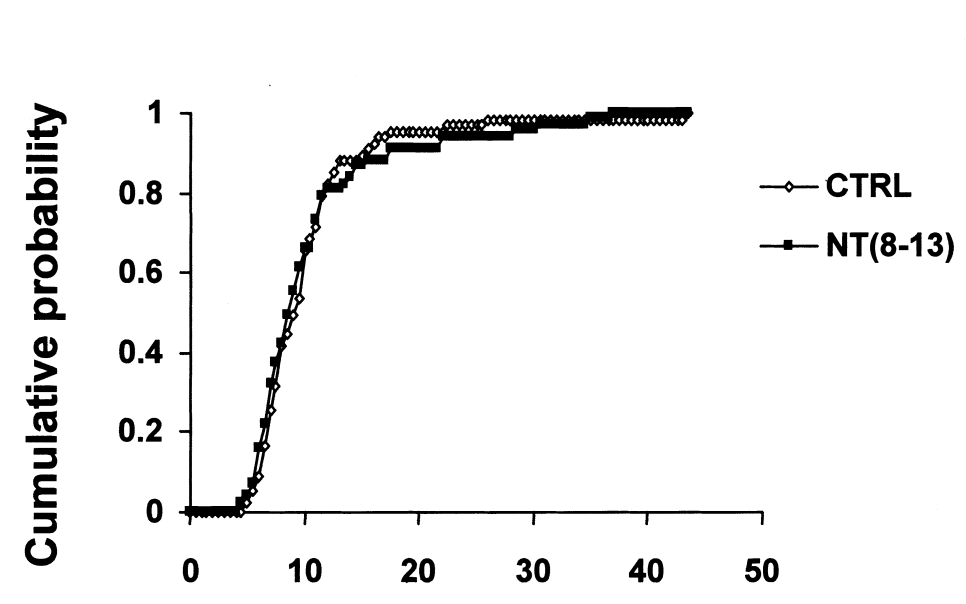

mEPSC amplitude (pA)

Fig. 3. NT(8-13) fails to stimulate the frequency of miniature synaptic events. (A) Immunofluorescence image showing abundant tyrosine hydroxylase-positive processes and varicosities surrounding a neurone $(\mathrm{N})$ that was voltage-clamped to record mEPSCs. Scale bar $=15 \mu \mathrm{m}$. (B) Whole-cell voltage-clamp recording from a VTA neurone at a holding potential of $-50 \mathrm{mV}$ in the presence of TTX $(0.5 \mu \mathrm{M})$ to block action potentials. The frequency of mEPSCs was not changed by NT(8-13) (100 $\mathrm{nM}$ ). (C) Cumulative probability distribution of mEPSC amplitudes recorded from the cell shown in (B), illustrating that NT(8-13) caused no significant modification of mEPSC amplitude. CTRL, control. 
experiments, we plated neurones on micro-droplets of substrate in order to obtain single neurone cultures ('micro-dot' cultures) (Fig. 4A) in which isolated VTA neurones develop synaptic contacts onto their own dendritic arbour (autapses) (Bourque and Trudeau, 2000; Congar and Trudeau, 1999; Sulzer et al., 1998). AMPA receptor-mediated autaptic EPSCs were evoked by brief depolarisation of isolated dopaminergic neurones (Fig. 4A). In autaptic current recording experiments performed on isolated dopaminergic neurones, the identity of the cell as dopaminergic was determined by immunolabelling for tyrosine hydroxylase (Fig. 4A) or by the sensitivity of its synaptic current to the D2 receptor agonist quinpirole (see Experimental procedures). We predicted that if $\mathrm{NT}(8-13)$ acted on nerve terminals to enhance $\mathrm{Ca}^{2+}$ entry or to directly facilitate neurotransmitter release, then autaptic EPSCs should be facilitated by NT(8-13). We found that autaptic EPSCs showed no detectable facilitation in the presence of 100 nM NT(8-13) (Fig. 4B). On average, the amplitude of autaptic EPSCs recorded $60 \mathrm{~s}$ after the introduction of the peptide was $88.0 \pm 15.2 \%$ of the amplitude of EPSCs during the control period ( $n=5$; Student's paired $t$-test, $P>0.05$ ). In these same cells, NT nonetheless caused a small amplitude slow inward current, detected as a shift in the holding current. The mean amplitude of these currents was $33.8 \pm 15.8 \mathrm{pA}(n=5)$ (not shown).

Although NT failed to directly enhance evoked EPSC amplitude, this does not directly exclude the possibility that NT receptors are present on the nerve terminals of dopaminergic neurones and play predominantly a modulatory role. For example, it has been proposed that NT receptors on dopaminergic neurones can decrease the efficacy of D2 autoreceptors to inhibit dopamine release (Fuxe et al., 1992; Li et al., 1995; Shi and Bunney, 1991; Tanganelli et al., 1989; von Euler et al., 1991; Werkman et al., 2000). To test this possibility, we evaluated whether NT(8-13) decreases the ability of the D2 receptor agonist quinpirole to cause presynaptic inhibition of action potential-evoked EPSCs in isolated dopaminergic neurones, a modulation that has been identified as being mediated at the level of the nerve terminals (Congar and Trudeau, 1999). As previously reported (Congar and Trudeau, 1999; Sulzer et al., 1998), quinpirole (5 $\mu \mathrm{M})$ caused a reduction in autaptic EPSC amplitude in dopaminergic neurones (Fig. 4C). This presynaptic effect of quinpirole was not accompanied by any detectable somatodendritic inward current. On average, EPSC amplitude was reduced to $49.0 \pm 6.9 \% \quad(n=10)$ (Student's paired $t$-test, $P<0.01$ ) of the control level 1 min after perfusion of quinpirole. This effect of quinpirole was reversible and highly reproducible. In neurones which were exposed twice to quinpirole, the first application caused an inhibition of $55.5 \pm 9.3 \%(n=6)$ while the second application, occurring $10 \mathrm{~min}$ later, caused an inhibition of $56.0 \pm 7.2 \% \quad(n=6)$. A paired comparison showed that this second inhibition was on average $109.2 \pm 12.0 \%$ of the first and not significantly different (Student's paired $t$-test, $P>0.05)$. In a second set of experiments, quinpirole was again applied twice, but the second time in the presence of $100 \mathrm{nM} \mathrm{NT(8-13).} \mathrm{In} \mathrm{these} \mathrm{experiments,}$ the first application of quinpirole reduced EPSC amplitudes by $55.4 \pm 9.4 \% \quad(n=5)$ (Student's paired $t$-test, $P<0.05$ ) (Fig. 4D). In the presence of NT(8-13), quinpirole still reduced EPSC amplitude in these cells, but only by $39.2 \pm 10.9 \%(n=5)$ (Fig. 4D). A paired comparison showed that this second inhibition in the presence of $\mathrm{NT}(8-13)$ was on average $68.5 \pm 8.6 \%$ of the first, which reflected a significant reduction of the effect of quinpirole (Student's paired $t$-test, $P<0.05$ ).

\section{DISCUSSION}

The present results provide evidence that NT modulates cultured dopaminergic neurones through at least two separate mechanisms. First, our spontaneous EPSC and action potential recording experiments indicate that NT acts at a somatodendritic level to enhance cellular excitability (Figs. 1, 2). A second mechanism at the level of the nerve terminals involves a modulatory function that can regulate the effectiveness of terminal D2-type dopamine receptors that normally inhibit neurotransmitter release from dopaminergic neurones (Fig. 4).

\section{Somatodendritic action}

Our results show that NT reliably increases action potential firing in cultured dopaminergic neurones. This observation confirms previous reports showing excitatory effects of NT on dopaminergic neurones (Pinnock, 1985; Seutin et al., 1989; Werkman et al., 2000). We have found that NT causes a small amplitude but long-lasting inward current (Fig. 1), much like the response which has been found in VTA slice preparations and demonstrated to result from the modulation of non-selective cationic conductances and potassium conductances (Farkas et al., 1996; Jiang et al., 1994). However, it is interesting to note that the enhancement in firing rate caused by NT was usually quite delayed in onset (Fig. 1). This suggests that the somatodendritic excitatory effect of NT may be complex and involve more than a simple depolarising action. Additional experiments will be required to examine this question.

\section{Action of NT on the nerve terminals of dopaminergic neurones}

Considering on the one hand that cultured dopaminergic neurones are known to establish glutamatergic synapses in vitro (Bourque and Trudeau, 2000) and on the other hand that neurotensin enhances action potential firing in dopaminergic neurones (Fig. 1D), it is to some extent not surprising that NT caused an increase in the frequency of spontaneous EPSCs in our experiments (Fig. 2). It appears that this enhancement was mainly due to the increase in firing rate caused by NT and not because of a direct presynaptic facilitation mechanism. This conclusion can be drawn from two observations. First, NT caused no significant increase in the amplitude of autaptic EPSCs (Fig. 4B). Second, the frequency of mEPSCs, recorded in the presence of TTX, was not 


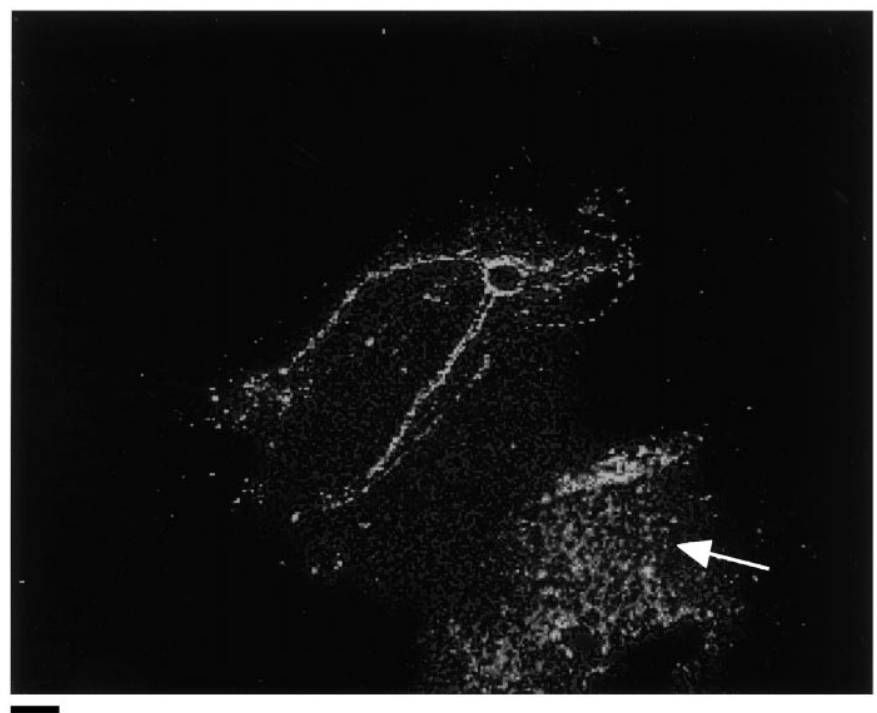

B
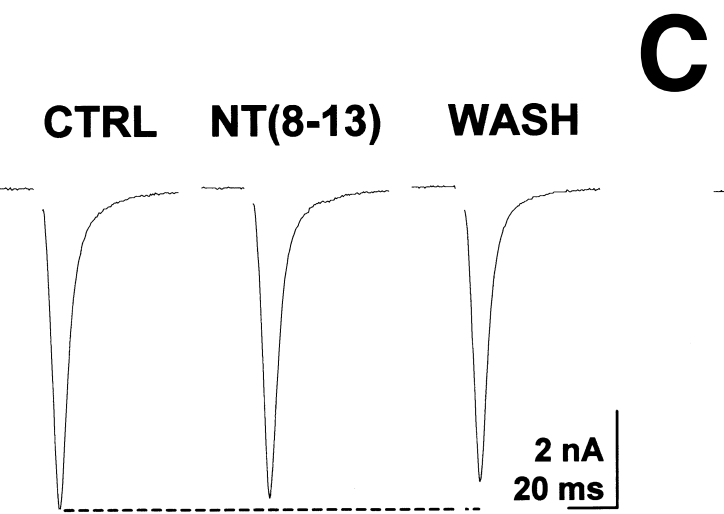

CTRL QUIN WASH

2 nA
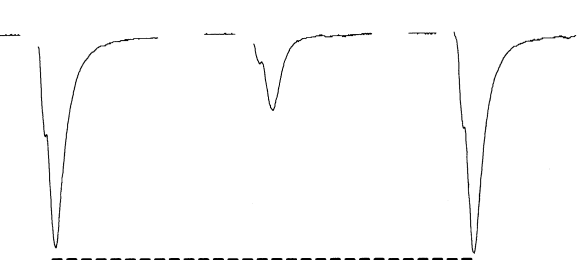

200 pA

$25 \mathrm{~ms}$

D
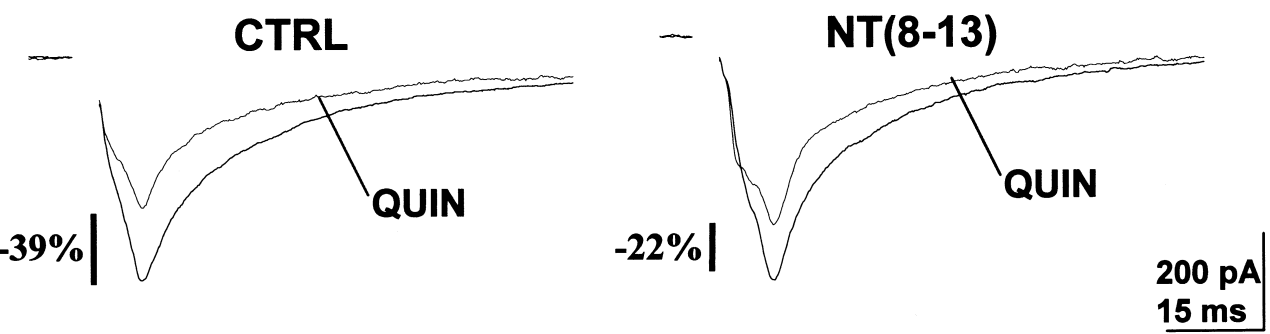

Fig. 4. Modulatory action of NT(8-13) on autaptic synaptic currents in isolated dopaminergic neurones. (A) Immunofluorescence image of an isolated tyrosine hydroxylase-positive neurone (top) in a 'micro-dot' culture. Fluorescent microspheres (arrow) were used to identify the recorded neurones following post-hoc immunostaining. The image represents a single 0.5 $\mu \mathrm{m}$ optical slice obtained after digital deconvolution of an image stack. Scale bar $=15 \mu \mathrm{m}$. (B) Whole-cell voltage-clamp recording from an isolated dopaminergic neurone at a holding potential of $-50 \mathrm{mV}$. A brief depolarising voltage step caused a CNQX-sensitive (not shown) glutamate-mediated synaptic current evoked by autaptic connections. The action current wave-

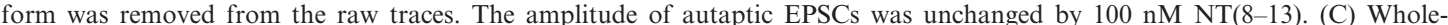
cell voltage-clamp recording from an isolated neurone at a holding potential of $-50 \mathrm{mV}$. A brief depolarising voltage step caused a glutamate-mediated synaptic current evoked by autaptic connections. The action current waveform was removed from the raw traces. The amplitude of autaptic EPSCs was significantly and reversibly inhibited by the D2 receptor agonist quinpirole (QUIN, $5 \mu \mathrm{M}$ ). (D) Whole-cell voltage-clamp recording of an autaptic EPSC in a different neurone. The holding potential was $-50 \mathrm{mV}$. The D2 agonist quinpirole (QUIN, $5 \mu \mathrm{M}$ ) reversibly decreased the amplitude of the EPSC (in this example, EPSC amplitude was reduced by $39 \%$ relative to control level). After a 10-min wash, a second application of quinpirole was performed in the presence of $100 \mathrm{nM} \mathrm{NT(8-13).} \mathrm{The} \mathrm{efficacy} \mathrm{of} \mathrm{quinpirole} \mathrm{was} \mathrm{reduced} \mathrm{in} \mathrm{the} \mathrm{presence} \mathrm{of}$ NT(8-13) (22\% reduction in EPSC amplitude relative to control level). CTRL, control. 
modified by NT (Fig. 3). This last observation suggests that NT receptors on nerve terminals do not mediate any substantial local depolarising action and do not cause a substantial rise in intra-terminal calcium.

Although we cannot exclude that differences may exist between the mechanisms of action of NT on cultured neurones and in vivo, our observations shed new light on the presynaptic mechanism of action of NT on dopaminergic neurones and suggest that the facilitation of dopamine release by NT observed in slices or in vivo may not necessarily be caused through a direct stimulation of nerve terminals in dopaminergic terminal fields (Bull and Sheehan, 1991; Faggin and Cubeddu, 1990; Heaulme et al., 1997; Hetier et al., 1988). Considering our finding of a lack of a direct excitatory effect on nerve terminals, two alternate mechanisms can be proposed to explain the observations made in slice preparations. One possibility is that NT acts on other elements within the striatum to indirectly facilitate dopamine release. For example, if NT receptors are present on glutamatergic terminals arising from the prefrontal cortex, NT could facilitate the spontaneous release of glutamate (Kalivas and Duffy, 1997), which would then act to depolarise dopaminergic nerve terminals. In support of this possibility, it has been shown that NT can cause an increase in the concentration of glutamate in the striatum in vivo (Ferraro et al., 1998, 1995). Although in an unrelated structure, neurotensin has also been shown to be able to increase the frequency of glutamate-mediated mEPSCs in the parabrachial nucleus slice preparation (Saleh et al., 1997). A second hypothesis, which does not exclude the first, is that NT enhances dopamine release by decreasing the effectiveness of dopamine autoreceptors on dopaminergic nerve terminals in the striatum. Such a hypothesis has been proposed previously (Tanganelli et al., 1989; von Euler et al., 1991) but, excluding the present work, is not currently supported by much direct evidence. Our finding that NT(8-13) decreased the ability of the D2 receptor agonist quinpirole to inhibit autaptic EPSCs generated in isolated dopaminergic neurones (Fig. 4D) provides evidence in favour of such an NT-D2 interaction directly at the level of dopaminergic nerve terminals. However, our results do not address whether this interaction occurs because of a direct modulation of the D2 receptor itself or at some step downstream in its signalling cascade. Much additional work will be required to identify the mechanism of this interaction in dopaminergic terminals.

Finally, it is important to note that in our experiments we have measured glutamate release from dopaminergic neurones and not dopamine release itself. Our findings thus need to be considered within the bounds of this limitation. However, a number of observations suggest that glutamate and dopamine release from cultured dopaminergic neurones may be regulated in very similar ways. First, although it has not been established whether glutamate and dopamine are contained in the same vesicles in these neurones, we have recently demonstrated that the vast majority of synaptic terminals established by cultured isolated dopaminergic neurones are immunopositive for the vesicular monoamine transporter
(Bourque and Trudeau, 2000), thereby suggesting that most have the capacity to package and presumably release dopamine. Second, all available evidence suggests that in cultured dopaminergic neurones, the synaptic release of glutamate is modulated in the same way as dopamine release. For example, we have shown recently that like what has been reported for dopamine release, synaptic glutamate release by dopaminergic neurones is up-regulated by the growth factor GDNF (glial cell linederived neurotrophic factor) (Bourque and Trudeau, 2000). In addition, we and others have shown that much like dopamine release, glutamate release from cultured dopaminergic neurones can be decreased by acute activation of D2-type dopamine receptors (i.e. 'autoreceptors') (Congar and Trudeau, 1999; Sulzer et al., 1998; present report). Together, the above-stated observations suggest that the mechanisms identified using the present experimental model provide valuable data contributing to a better understanding of the cellular and molecular mechanisms of action of NT on dopaminergic neurones.

\section{Implication of NT receptors}

In the present set of experiments, we have not identified which NT receptor subtype mediates the observed physiological effects. However, the increase in spontaneous EPSC frequency caused by NT(8-13) is blocked by SR142948A, a compound with high affinity for both type 1 (NTR1) and type 2 NT (NTR2) receptors (Gully et al., 1997; Trudeau, L.-E., unpublished results). It has been proposed that dopaminergic neurones preferentially express NTR1 and not NTR2, which may be preferentially expressed in astrocytes (Nouel et al., 1997). It is thus likely that most effects observed here were mediated by NTR1.

In conclusion, the present set of results provide new information on the cellular mechanism of action of NT on dopaminergic neurones. First, our experiments on glutamate-mediated EPSCs and mEPSCs provide the first direct evidence that, at least in culture, NT does not directly stimulate the nerve terminals of dopaminergic neurones. Second, our demonstration that NT reduces the efficacy of a D2 receptor agonist to inhibit neurotransmitter release at the terminals of dopaminergic neurones provides evidence suggesting that an important role of terminal NT receptors is to locally modulate the efficacy of presynaptic inhibition. The signalling pathways mediating this NT-D2 receptor interaction will need to be determined.

\footnotetext{
Acknowledgements-This work was supported in part by the Canadian Institutes of Health Research (former Medical Research Council of Canada), the EJLB Foundation and the Fonds de la Recherche en Santé du Québec. M.L. was supported by a postdoctoral fellowship from the Natural Sciences and Engineering Research Council of Canada. P.C. and F.J.M. are supported by fellowships from the Groupe de Recherche sur le Système Nerveux Central of the Université de Montréal. P.C. also received support from the Canada Neuroscience Foundation. We thank Dr. Pierre-Paul Rompré for helpful comments on an earlier version of this manuscript and Claudia Jomphe for expert assistance with immunocytochemistry.
} 


\section{REFERENCES}

Alonso, A., Faure, M.P., Beaudet, A., 1994. Neurotensin promotes oscillatory bursting behavior and is internalized in basal forebrain cholinergic neurons. J. Neurosci. 14, 5778-5792.

Audinat, E., Hermel, J.M., Crepel, F., 1989. Neurotensin-induced excitation of neurons of the rat's frontal cortex studied intracellularly in vitro. Exp. Brain Res. 78, 358-368.

Bissette, G., Nemeroff, C.B., Loosen, P.T., Prange, A.J.J., Lipton, M.A., 1976. Hypothermia and intolerance to cold induced by intracisternal administration of the hypothalamic peptide neurotensin. Nature 262, 607-609.

Bourque, M.J., Trudeau, L.E., 2000. GDNF enhances the synaptic efficacy of dopaminergic neurons in culture. Eur. J. Neurosci. 12, 3172-3180.

Bull, D.R., Sheehan, M.J., 1991. Presynaptic regulation of electrically evoked dopamine overflow in nucleus accumbens: a pharmacological study using fast cyclic voltammetry in vitro. Naunyn Schmiedebergs Arch. Pharmacol. 343, 260-265.

Carraway, R., Leeman, S.E., 1973. The isolation of a new hypotensive peptide, neurotensin, from bovine hypothalami. J. Biol. Chem. 248, 6854 6861.

Cheramy, A., Desce, J.M., Godeheu, G., Glowinski, J., 1994. Presynaptic control of dopamine synthesis and release by excitatory amino acids in rat striatal synaptosomes. Neurochem. Int. 25, 145-154.

Congar, P., Trudeau, L.E., 1999. On the mechanism of modulation of glutamate release by presynaptic dopamine receptors in dopaminergic neurons of the ventral tegmental area. Soc. Neurosci. Abstr. 25, 1258.

Desce, J.M., Godeheu, G., Galli, T., Artaud, F., Cheramy, A., Glowinski, J., 1991. Presynaptic facilitation of dopamine release through D,Lalpha-amino-3-hydroxy-5-methyl-4-isoxazole propionate receptors on synaptosomes from the rat striatum. J. Pharmacol. Exp. Ther. 259, 692698

Faggin, B.M., Cubeddu, L.X., 1990. Rapid desensitization of dopamine release induced by neurotensin and neurotensin fragments. J. Pharmacol. Exp. Ther. 253, 812-818

Faggin, B.M., Zubieta, J.K., Rezvani, A.H., Cubeddu, L.X., 1990. Neurotensin-induced dopamine release in vivo and in vitro from substantia nigra and nucleus caudate. J. Pharmacol. Exp. Ther. 252, 817-825.

Farkas, R.H., Chien, P.Y., Nakajima, S., Nakajima, Y., 1996. Properties of a slow nonselective cation conductance modulated by neurotensin and other neurotransmitters in midbrain dopaminergic neurons. J. Neurophysiol. 76, 1968-1981.

Ferraro, L., Antonelli, T., O'Connor, W.T., Fuxe, K., Soubrie, P., Tanganelli, S., 1998. The striatal neurotensin receptor modulates striatal and pallidal glutamate and GABA release: functional evidence for a pallidal glutamate-GABA interaction via the pallidal-subthalamic nucleus loop. J. Neurosci. 18, 6977-6989.

Ferraro, L., O'Connor, W.T., Antonelli, T., Fuxe, K., Tanganelli, S., 1997. Differential effects of intrastriatal neurotensin(1-13) and neurotensin(8-13) on striatal dopamine and pallidal GABA release. A dual-probe microdialysis study in the awake rat. Eur. J. Neurosci. 9 , $1838-1846$.

Ferraro, L., Tanganelli, S., O’Connor, W.T., Bianchi, C., Ungerstedt, U., Fuxe, K., 1995. Neurotensin increases endogenous glutamate release in the neostriatum of the awake rat. Synapse 20, 362-364.

Fuxe, K., O’Connor, W.T., Antonelli, T., Osborne, P.G., Tanganelli, S., Agnati, L.F., Ungerstedt, U., 1992. Evidence for a substrate of neuronal plasticity based on pre- and postsynaptic neurotensin-dopamine receptor interactions in the neostriatum. Proc. Natl. Acad. Sci. USA 89, 55915595.

Glowinski, J., Cheramy, A., Romo, R., Barbeito, L., 1988. Presynaptic regulation of dopaminergic transmission in the striatum. Cell Mol. Neurobiol. 8, 7-17.

Gully, D., Labeeuw, B., Boigegrain, R., Oury-Donat, F., Bachy, A., Poncelet, M., Steinberg, R., Suaud-Chagny, M.F., Santucci, V., Vita, N., Pecceu, F., Labbe-Jullie, C., Kitabgi, P., Soubrie, P., Le Fur, G., Maffrand, J.P., 1997. Biochemical and pharmacological activities of SR 142948A, a new potent neurotensin receptor antagonist. J. Pharmacol. Exp. Ther. 280, 802-812.

Heaulme, M., Leyris, R., Le Fur, G., Soubrie, P., 1997. Involvement of potentially distinct neurotensin receptors in neurotensin-induced stimulation of striatal $[3 \mathrm{H}]$ dopamine release evoked by $\mathrm{KCl}$ versus electrical depolarization. Neuropharmacology $36,1447-1454$

Hetier, E., Boireau, A., Dubedat, P., Blanchard, J.C., 1988. Neurotensin effects on evoked release of dopamine in slices from striatum, nucleus accumbens and prefrontal cortex in rat. Naunyn Schmiedebergs Arch. Pharmacol. 337, 13-17.

Holmes, L.J., Wise, R.A., 1985. Dopamine-dependent contralateral circling induced by neurotensin applied unilaterally to the ventral tegmental area in rats. Brain Res. Bull. 15, 537-538.

Jiang, Z.G., Pessia, M., North, R.A., 1994. Neurotensin excitation of rat ventral tegmental neurones. J. Physiol. (Lond.) 474, 119-129.

Jolas, T., Aghajanian, G.K., 1996. Neurotensin excitation of serotonergic neurons in the dorsal raphe nucleus of the rat in vitro. Eur. J. Neurosci. $8,153-161$.

Jolicoeur, F.B., St-Pierre, S., Aube, C., Rivest, R., Gagne, M.A., 1984. Relationships between structure and duration of neurotensin's central action: emergence of long acting analogs. Neuropeptides 4, 467-476.

Kalivas, P.W., Duffy, P., 1990. Effect of acute and daily neurotensin and enkephalin treatments on extracellular dopamine in the nucleus accumbens. J. Neurosci. 10, 2940-2949.

Kalivas, P.W., Duffy, P., 1997. Dopamine regulation of extracellular glutamate in the nucleus accumbens. Brain Res. 761, 173-177.

Kitabgi, P., Herve, D., Studler, J.M., Tramu, G., Rostene, W., Tassin, J.P., 1989. Neurotensin/dopamine interactions. Encephale 15, 91-94.

Lacey, M.G., Mercuri, N.B., North, R.A., 1989. Two cell types in rat substantia nigra zona compacta distinguished by membrane properties and the actions of dopamine and opioids. J. Neurosci. 9, 1233-1241.

Laitinen, K., Crawley, J.N., Mefford, I.N., De Witte, P., 1990. Neurotensin and cholecystokinin microinjected into the ventral tegmental area modulate microdialysate concentrations of dopamine and metabolites in the posterior nucleus accumbens. Brain Res. 523, 342-346.

Li, X.M., Ferraro, L., Tanganelli, S., O'Connor, W.T., Hasselrot, U., Ungerstedt, U., Fuxe, K., 1995. Neurotensin peptides antagonistically regulate postsynaptic dopamine D2 receptors in rat nucleus accumbens: a receptor binding and microdialysis study. J. Neural Transm. Gen. Sect. 102, 125-137.

Michel, F.J., Trudeau, L.E., 2000. Clozapine inhibits synaptic transmission at GABAergic synapses established by ventral tegmental area neurones in culture. Neuropharmacology 39, 1536-1543.

Mienville, J.M., Vicini, S., 1987. A pyridazinyl derivative of gamma-aminobutyric acid (GABA), SR 95531, is a potent antagonist of Cl- channel opening regulated by GABAA receptors. Neuropharmacology 26, 779-783.

Nalivaiko, E., Michaud, J.C., Soubrie, P., Le Fur, G., 1998. Electrophysiological evidence for putative subtypes of neurotensin receptors in guineapig mesencephalic dopaminergic neurons. Neuroscience 86, 799-811.

Nouel, D., Faure, M.P., St. Pierre, J.A., Alonso, R., Quirion, R., Beaudet, A., 1997. Differential binding profile and internalization process of neurotensin via neuronal and glial receptors. J. Neurosci. 17, 1795-1803.

Pinnock, R.D., 1985. Neurotensin depolarizes substantia nigra dopamine neurones. Brain Res. 338, 151-154.

Quirion, R., 1983. Interactions between neurotensin and dopamine in the brain: an overview. Peptides 4, 609-615. 
Quirion, R., Chiueh, C.C., Everist, H.D., Pert, A., 1985. Comparative localization of neurotensin receptors on nigrostriatal and mesolimbic dopaminergic terminals. Brain Res. 327, 385-389.

Rayport, S., Sulzer, D., Shi, W.X., Sawasdikosol, S., Monaco, J., Batson, D., Rajendran, G., 1992. Identified postnatal mesolimbic dopamine neurons in culture: morphology and electrophysiology. J. Neurosci. 12, 42644280.

Romo, R., Cheramy, A., Godeheu, G., Glowinski, J., 1986. In vivo presynaptic control of dopamine release in the cat caudate nucleus-III. Further evidence for the implication of corticostriatal glutamatergic neurons. Neuroscience 19, 1091-1099.

Rompre, P.P., Bauco, P., Gratton, A., 1992. Facilitation of brain stimulation reward by mesencephalic injections of neurotensin-(1-13). Eur. J. Pharmacol. 211, 295-303.

Rompre, P.P., Gratton, A., 1992. A comparison of the effects of mesencephalic injections of neurotensin(1-13) and neuromedin N on brain electrical self-stimulation. Peptides 13, 713-719.

Rompre, P.P., Gratton, A., 1993. Mesencephalic microinjections of neurotensin-(1-13) and its C-terminal fragment, neurotensin-(8-13), potentiate brain stimulation reward. Brain Res. 616, 154-162.

Rompre, P., Perron, S., 2000. Evidence for a role of endogenous neurotensin in the initiation of amphetamine sensitization. Neuropharmacology 39, 1880-1892.

Rostene, W., Azzi, M., Boudin, H., Lepee, I., Souaze, F., Mendez-Ubach, M., Betancur, C., Gully, D., 1997. Use of nonpeptide antagonists to explore the physiological roles of neurotensin. Focus on brain neurotensin/dopamine interactions. Ann. N. Y. Acad. Sci. 814, $125-141$.

Saleh, T.M., Kombian, S.B., Zidichouski, J.A., Pittman, Q.J., 1997. Cholecystokinin and neurotensin inversely modulate excitatory synaptic transmission in the parabrachial nucleus in vitro. Neuroscience 77, 23-35.

Schotte, A., Leysen, J.E., 1989. Autoradiographic evidence for the localization of high affinity neurotensin binding sites on dopaminergic nerve terminals in the nigrostriatal and mesolimbic pathways in rat brain. J. Chem. Neuroanat. 2, $253-257$.

Seroogy, K., Ceccatelli, S., Schalling, M., Hokfelt, T., Frey, P., Walsh, J., Dockray, G., Brown, J., Buchan, A., Goldstein, M., 1988. A subpopulation of dopaminergic neurons in rat ventral mesencephalon contains both neurotensin and cholecystokinin. Brain Res. 455 , 88-98.

Seutin, V., Massotte, L., Dresse, A., 1989. Electrophysiological effects of neurotensin on dopaminergic neurones of the ventral tegmental area of the rat in vitro. Neuropharmacology 28, 949-954.

Shi, W.X., Bunney, B.S., 1991. Neurotensin modulates autoreceptor mediated dopamine effects on midbrain dopamine cell activity. Brain Res. $543,315-321$

Sotty, F., Brun, P., Leonetti, M., Steinberg, R., Soubrie, P., Renaud, B., Suaud-Chagny, M.F., 2000. Comparative effects of neurotensin, neurotensin(8-13) and (D-Tyr(11))neurotensin applied into the ventral tegmental area on extracellular dopamine in the rat prefrontal cortex and nucleus accumbens. Neuroscience 98, 485-492.

Sotty, F., Souliere, F., Brun, P., Chouvet, G., Steinberg, R., Soubrie, P., Renaud, B., Suaud-Chagny, M.F., 1998. Differential effects of neurotensin on dopamine release in the caudal and rostral nucleus accumbens: a combined in vivo electrochemical and electrophysiological study. Neuroscience 85, 1173-1182.

Steinberg, R., Brun, P., Souilhac, J., Bougault, I., Leyris, R., Le Fur, G., Soubrie, P., 1995. Neurochemical and behavioural effects of neurotensin vs (D-Tyr11)neurotensin on mesolimbic dopaminergic function. Neuropeptides 28, 43-50.

Sulzer, D., Joyce, M.P., Lin, L., Geldwert, D., Haber, S.N., Hattori, T., Rayport, S., 1998. Dopamine neurons make glutamatergic synapses in vitro. J. Neurosci. 18, 4588-4602.

Tanganelli, S., von Euler, G., Fuxe, K., Agnati, L.F., Ungerstedt, U., 1989. Neurotensin counteracts apomorphine-induced inhibition of dopamine release as studied by microdialysis in rat neostriatum. Brain Res. 502, 319-324.

Trudeau, L.E., 2000. Neurotensin regulates intracellular calcium in ventral tegmental area astrocytes: evidence for the involvement of multiple receptors. Neuroscience 97, 293-302.

von Euler, G., van der Ploeg, I., Fredholm, B.B., Fuxe, K., 1991. Neurotensin decreases the affinity of dopamine D2 agonist binding by a G protein-independent mechanism. J. Neurochem. 56, 178-183.

Werkman, T.R., Kruse, C.G., Nievelstein, H., Long, S.K., Wadman, W.J., 2000. Neurotensin attenuates the quinpirole-induced inhibition of the firing rate of dopamine neurons in the rat substantia nigra pars compacta and the ventral tegmental area. Neuroscience 95, 417-423.

Wu, T., Li, A., Wang, H.L., 1995. Neurotensin increases the cationic conductance of rat substantia nigra dopaminergic neurons through the inositol 1,4,5-trisphosphate-calcium pathway. Brain Res. 683, 242-250.

(Accepted 30 November 2001) 